\title{
Time series trend analysis of temperature and rainfall in lake Tana Sub-basin, Ethiopia
}

\author{
Solomon Addisu*, Yihenew G. Selassie, Getachew Fissha and Birhanu Gedif
}

\begin{abstract}
Background: To identify and quantify the impact of climate change on socio-economic sectors and ecosystems, many global studies have been carried out and policy changes for mitigation and adaptation were recommended. However, the old-fashioned top-down approach, global study, has little local and regional specificity and has failed to address the regional and local consequences of climate change. Thus, this research was conducted in filling such knowledge gaps in Lake Tana sub-basin. The research was aimed at addressing the national and local issues of climate change and was done by analyzing time series temperature and rainfall trends in the highlands of Ethiopia and LTSB in particular. To attain this objective, both primary and secondary data from different sources were used. The collected data were analyzed following quantitative and qualitative analysis methods and Manna Kendall Trend test method was used.
\end{abstract}

Results: The main findings revealed that the mean, maximum and minimum temperature had a general increasing trend; whereas, rainfall amount showed a general decreasing trend in Lake Tana Sub-basin. Analysis of the 40 years annual total rainfall data from 109 representative ground based meteorological stations in Ethiopia indicated a coefficient of variation ranging from 20 to $89 \%$. Of the 109 stations considered, 17 had above $42 \%$ coefficient of variation highlighting the extreme variability of rainfall over the country

Conclusions: To conclude, development planners should design strategies and plans by taking into account a declining summer rainfall and increasing temperature impacts on rural livelihoods.

Keywords: Climate change and variability, Temperature trend, Rainfall trend, Manna Kendall trend test

\section{Background}

The Intergovernmental Panel on Climate Change (IPCC) in its fifth assessment synthesis report observed that warming of the climate system is unequivocal, and since the 1950s, many of the observed changes are unprecedented. Human influence on the climate system is clear and recent anthropogenic emissions of greenhouse gases are the highest in history and recent climate change have had widespread impacts on life and life support systems (IPCC 2014). In the IPCC fourth assessment report, it was also clearly stated that the warming of the climate system is explicit by the existing evidences from

*Correspondence: soladd2000@yahoo.com

Department of Natural Resources Management, College of Agriculture

and Environmental Sciences, Bahir Dar University, Bahir Dar, Ethiopia observations of widespread melting of snow and ice, increases in global average air and ocean temperature and rising global sea level.

Climate change negotiations and plans have so far been exclusively targeted on GHGs mitigation. Regardless of widespread and long-standing demand from developing countries for greater emphasis on adaptation strategies, the climate change conventions and negotiations have only recently started paying serious attention to adaptation aspects of climate change strategy actions. The United Nations Framework Convention on Climate Change (UNFCCC 2006) refers to adaptation only in the context of the actual climate change situations. It implies that without greenhouse gas emissions, there is no climate change and hence no need for adaptation measures.

\section{Springer}


Based on this, widely accepted interpretation, adaptation measures are urgently important since mitigation of greenhouse gases will not completely halt climate change related hazards. Adaptation measures are so essential to deal with the unavoidable adverse consequences of climate change to which the world is already committed (IPCC 2007a).

For vulnerable communities, adaptation measures should be based on their livelihood characteristics. By taking into consideration of the dynamics of the poor and their livelihoods, it is clear to understand how they will be affected by climate change hazards, how they might respond with the resources they have, and how these conditions can be replicated and built upon for successful adaptation strategies. By protecting and enhancing the natural services that support source of revenue, exposed communities can continue local safety nets and expand the range of options for adaptation with troublesome shocks and trends (IPCC 2003). Agriculture is the most susceptible sector to climate change related hazards. This is due to the fact that climate change affects two of the most important direct agricultural production inputs and these are precipitation and temperature (Philip et al. 2014). Climate change also indirectly affects agriculture by influencing emergence and distribution of crop pests and livestock diseases, worsening the frequency and dissemination of adverse weather disorders, decreasing water supplies and irrigation; and enhancing severity of soil erosion (Watson 2001; IPCC 2001a, b).

Any minor changes in rainfall intensity or amount impose a severe challenge on the rural people since its main livelihood depends on agriculture which mostly relies on summer monsoon. This is because modeling or predicting climate change impact on predominantly subsistent farmers at global level is a very difficult task due to the lack of ordinary descriptions, lack or difficulty to get benchmark data, unique location, and the households' ability to integrate on-farm and off-farm activities, and lastly the farmers' susceptibility to a range of stressors (IPCC 2007b). The overall objective of this research was, therefore, to fill such research gaps thorough analyzing time series temperature and rainfall trends in the highlands of Ethiopia and LTSB in particular.

\section{Methods}

\section{Description of the study area}

Ethiopia is located in Northeastern or East Central Horn of Africa lying between $3^{\circ}$ and $15^{\circ}$ north latitude, $33^{\circ}-48^{\circ}$ east longitude (Fig. 1). Ethiopia is bordered in the east by Somalia and Djibouti, in the south by Kenya, in the north and northeast by Eritrea and in the west by the North and South Sudan. The country has a total area of about 1.1 million $\mathrm{km}^{2}$ and comprises of 12 river basins with varying size and water resource potential (CSA 2007). Blue Nile basin (Locally called the Abay Basin), the largest river basin in Ethiopia, is one of those basins which consist of Lake Tana Sub-basin. Lake Tana is the largest freshwater and oligotrophic-high altitude lake in the world (CSA 2007).

This study was conducted in Lake Tana Sub-basin (LTSB) which is designated as one of the development corridors in the country and huge investments are being incurred to promote large scale farmer managed irrigation and also to generate hydroelectric power. It is found in the Amhara National Regional State (ANRS) and is situated within the upper reaches of the Blue Nile River. It is located within latitudinal and longitudinal ranges between $10^{\circ} 58^{\prime} \mathrm{N}$ to $12^{\circ} 47^{\prime} \mathrm{N}$ and $36^{\circ} 45^{\prime} \mathrm{E}$ to $38^{\circ} 14^{\prime} \mathrm{E}$, respectively. It covers a total area of 1,589,654.98 ha.

\section{Data collection}

National Center for Environmental Predictions (NCEP) data

Observations are from many different sources, including satellites, ships, ground stations, and radar. Currently, earth system research laboratory, physical sciences division (PSD) makes available these reanalysis datasets to the public in standard netCDF file format at the website: http://journals.ametsoc.org/doi/pdf/10.1175/1520 0477(1996)077\%3C0437\%3ATNYRP\%3E2.0.CO\%3B2. Reanalysis is a method to reconstruct the past state of the atmosphere and oceans in a coherent way by combining available observations with numerical models. These reconstructions are created with model based data assimilation methods which are similar to those used for numerical weather prediction (Compo et al. 2011). NCEP Reanalysis is also scientific method for developing a comprehensive record of how weather and climate are changing. The meteorological observation data were grouped based on the respective agro-ecology and the representative data were taken for climate trend analysis of the study area. XLSTAT computer software program was employed to analyze the trend analysis and to consider the seasonal component of rainfall at the same time. Hence, to describe a trend of time series, Mann-Kendall trend test was used to see whether there is a decreasing or increasing trend. Mann-Kendall statistics (S) is one of the non-parametric statistical tests used for detecting trends of climatic elements. Mann-Kendall trend test is also the most widely used methods since it is less sensitive to outliers (extraordinary high values within time series data) and it is the most robust as well as suitable for detecting trends in rainfall (Keradin et al. 2013).

\section{Data analysis}

A score of +1 is awarded if the value in a time series is larger, or a score of -1 is awarded if it is reduced. The 


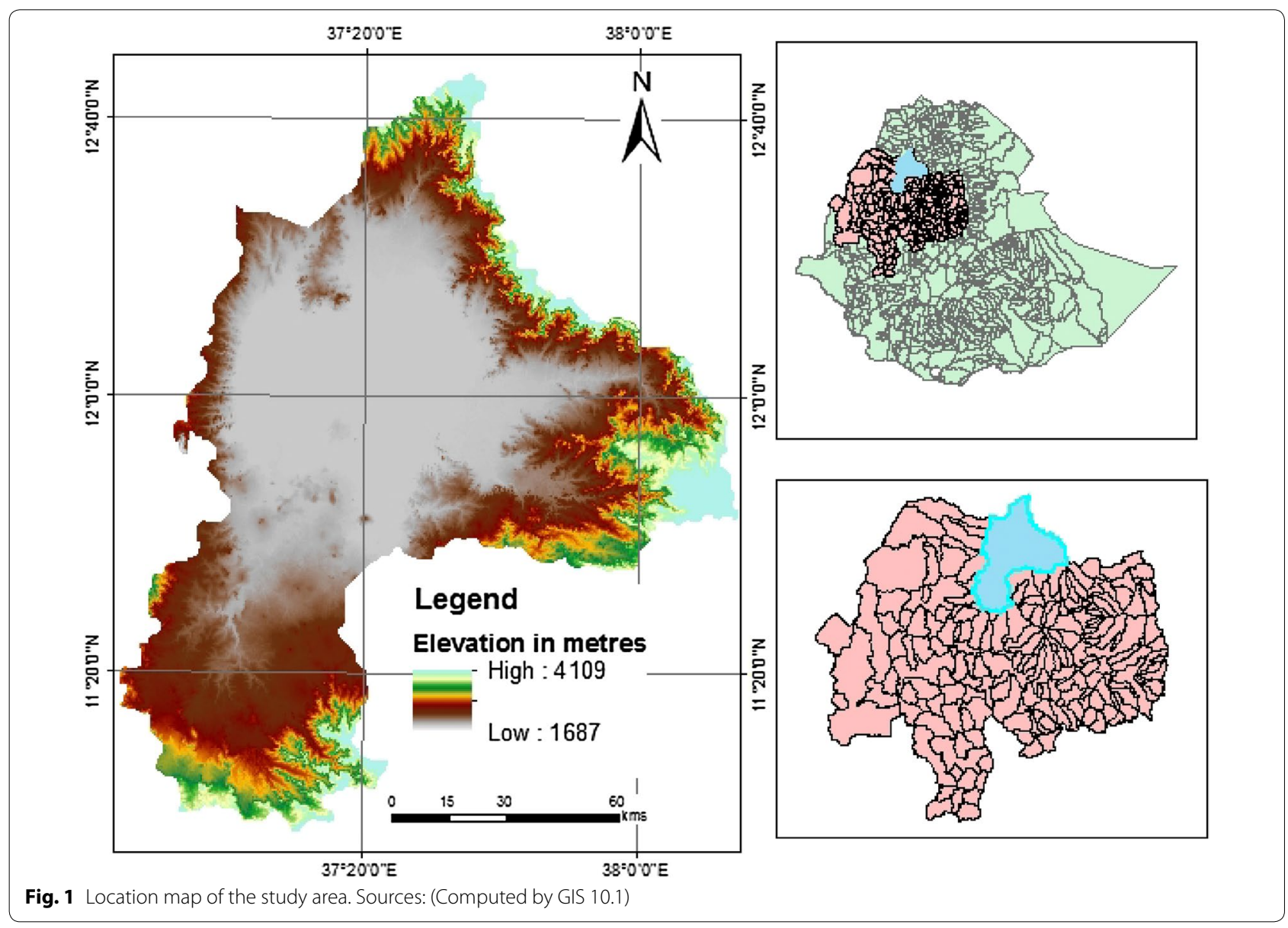

overall score for the time-series data is the Mann-Kendalll statistic which is then compared to a critical value to test whether the trend in rainfall or temperature is increasing, decreasing or if no trend can be observed. The strength of the trend is proportional to the magnitude of the Mann-Kendall Statistic. $\operatorname{Sgn}(\mathrm{Xj}-\mathrm{X} \mathrm{k})$ is an indicator function that results in the values 1,0 , or -1 according to the significance of $\mathrm{Xj}-\mathrm{Xk}$ where $\mathrm{j}>\mathrm{k}$, the function is calculated as follows:

$$
\begin{aligned}
& \operatorname{sgn}(X j-X k)=1 \rightarrow \text { if, } X j-X k>0 \\
& \operatorname{sgn}(X j-X k)=0 \rightarrow \text { if }, X j-X k=0 \\
& \operatorname{sgn}(X j-X k)=-1 \rightarrow \text { if, } X j-X k<0
\end{aligned}
$$

where $X j$ and $X k$ are the sequential rainfall or temperature values in months $J$ and $K(J>k)$ respectively; whereas, a positive value is an indicator of increasing (upward) trend and a negative value is an indicator of decreasing (downward) trend.

In the equation, $\mathrm{X} 1, \mathrm{X} 2, \mathrm{X} 3, \ldots, \mathrm{Xn}$ represents ' $\mathrm{n}$ ' data points (monthly), where $\mathrm{Xj}$ represents the data point at time J. Then the Mann-Kendall statistics (S) is defined as the sum of the number of positive differences minus the number of negative differences, given by:

$$
S=\sum_{k=1}^{n-1} \sum_{j=k+n}^{n} \operatorname{sgn}(X j-X k)
$$

where

$$
\begin{aligned}
& \operatorname{sgn}(X j-X k)=1 \rightarrow \text { if, } X j-X k>0 \\
& \operatorname{sgn}(X j-X k)=0 \rightarrow \text { if, } X j-X k=0 \\
& \operatorname{sgn}(X j-X k)=-1 \rightarrow \text { if, } X j-X k<0
\end{aligned}
$$

Trends considered at the study sites were tested for significance. A normalized test statistic (Z-score) is used to check the statistical significance of the increasing or decreasing trend of mean precipitation and temperature values. The trends of temperature are determined and their statistical significance is tested using Mann-Kendall trend significant test with the level of significance 0.05 $\left(Z_{-} \alpha / 2= \pm 1.96\right)$. 


$$
\begin{aligned}
& Z=\frac{n-1}{\sqrt{\operatorname{var}(S)}} \rightarrow \text { if }, S>0 \\
& Z=0 \rightarrow \text { if }, S=0 \\
& Z=\frac{n-1}{\sqrt{\operatorname{var}(S)}} \rightarrow \text { if }, S<0
\end{aligned}
$$

Hypothesis testing $\mathrm{H}_{\mathrm{o}}=\mu=\mu \mathrm{o}$ (there is no significant trend/stable trend in the data)

$\mathrm{H}_{\mathrm{a}}=\mu \_\mu \mathrm{o}$ (there is a significant trend/unstable trend in the data) If $-\mathrm{Z}_{1-\alpha / 2} \leq \mathrm{Z} \leq \mathrm{Z}_{1-\alpha / 2}$ accepts the hypothesis or else reject the null hypothesis. Powerfully increasing or decreasing trends indicate a higher level of statistical significance (Keredin et al. 2013).

\section{Results and discussions}

\section{Rainfall and temperature trends in Ethiopia}

Analysis of the 40 years annual total rainfall data from 109 representative ground based meteorological stations in Ethiopia indicated a coefficient of variation ranging from 20 to $89 \%$. Of the 109 stations considered, 17 had above $52 \%$ coefficient of variation highlighting the extreme variability of rainfall over the country (Fig. 2). According to Hare (2003), CV is used to classify the degree of variability of rainfall events as less $(\mathrm{CV}<20)$, moderate $(20<\mathrm{CV}<30)$, and high $(\mathrm{CV}>30)$. Based on this, Ethiopian rainfall is highly variable, especially in the area where agricultural dependent rural people are densely populated (highland regions). Moreover, rainfall variability is also higher for most of the stations in the area where agricultural activities are the main livelihood.

For the highest rainfall dependent Ethiopian agriculture, the amount and distribution of the rainfall during the crop growing seasons are critical (Gebre et al. 2013). They also stated that in Ethiopia, the start and end of the rain, its patterns of distribution, frequency and probability of dry spells in the growing season, most commonly summer, are key factors affecting planning, performance, and management of agricultural operations. This is because unusual rainfall amount and distributions usually lead to poor harvest and/or complete crop failure and shortage of pasture and animal feeds.

According to the rainfall data analysis, the mean annual rainfall ranges from $2000 \mathrm{~mm}$ in the highland areas in the southwest part and less than $250 \mathrm{~mm}$ in the eastern and southeastern lowland parts of the country. In general, annual precipitation ranges from 800 to $2200 \mathrm{~mm}$ in the highlands ( $>1500 \mathrm{~m}$ above sea level.) and varies from less than 200 to $800 \mathrm{~mm}$ in the lowlands $(<1500 \mathrm{~m}$ above sea level). Rainfall also decreases northwards and eastwards from the high rainfall areas in the southwest (Fig. 3). The distribution of rainfall is also uneven for both rain seasons. The summer rainfall covers most of the highlands of the country and lasts from the months of June to September for a year. The results of the long year rainfall analysis show that summer rainfall amount has been declining. On the other hand, the southern parts of the country are

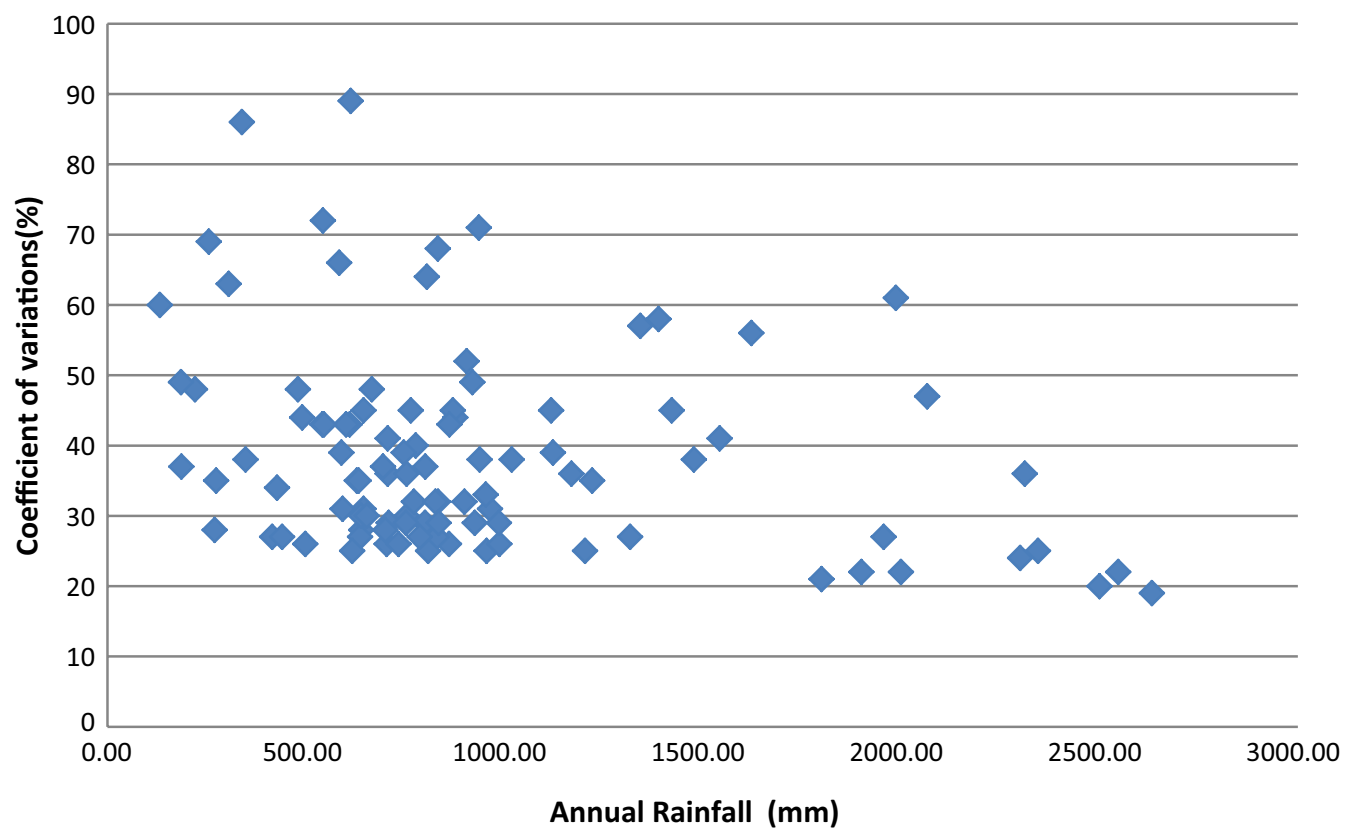

Fig. 2 Mean annual amount of rainfall and its coefficient of variation (CV) 


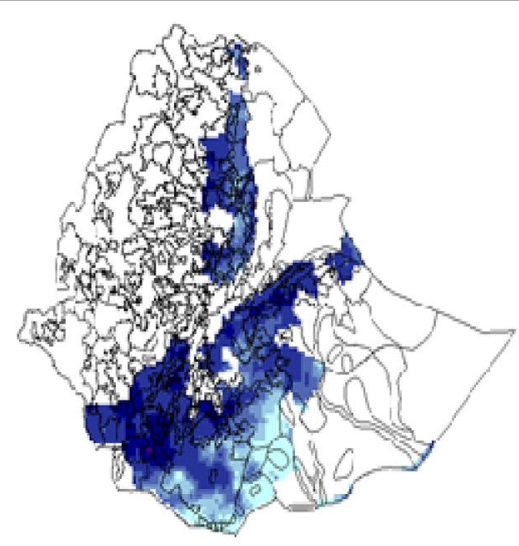

RF distribution (March to May)
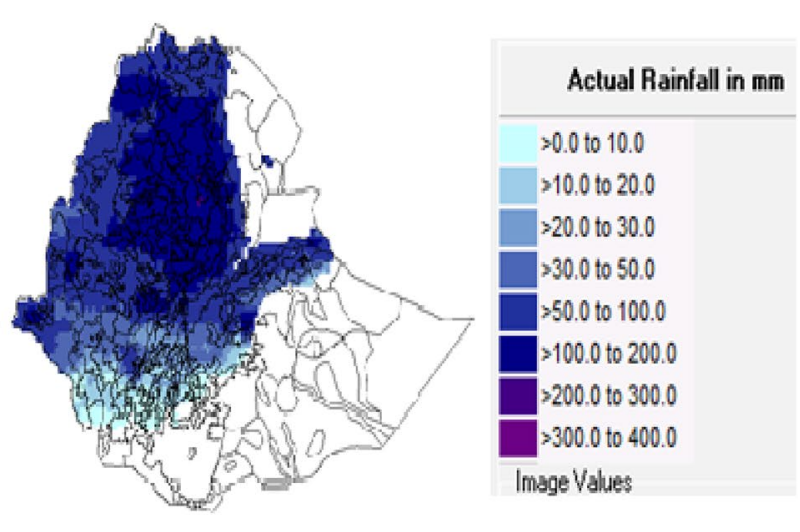

RF distribution (June to sept)

Fig. 3 Belg (March to May) and kiremt (June-September) rainfall distribution (Source: computed from LEAP and NCEP, 2010)

receiving maximum rain during the months of March to May and a similar trend has recorded.

Recorded meteorological data analysis of temperature also indicates that increasing trends have been observed almost in all parts of the country. Based on the NCEP reanalysis datasets for climate diagnostics, products from IPCC data distribution center by assimilating climate observations, satellite, ground stations, observations above the top of the atmosphere and radar indicate that the mean monthly temperature of Ethiopia is increasing (Fig. 4).

Similar studies by the UNDP climate change profile for Ethiopia (2008), also show that the mean annual temperature increased by $1.3{ }^{\circ} \mathrm{C}$ between 1960 and 2006. The temperature increase has been most rapid from July to September $\left(0.32{ }^{\circ} \mathrm{C}\right.$ per decade). It is also reported that the average number of hot days and the number of hot nights per year between 1960 and 2006 has increased by 73 and 137, respectively. The rate of temperature change was highest in rainy season in the months of June, July and August.

\section{Annual and monthly rainfall trends and MT in LTSB}

The monthly and annual rainfall analysis from the meteorological stations of LTSB was made based on the availability and reliability of the observed gauge stations. The meteorological stations such as Bahir Dar, Yifag, Hamusit, Zeghie and Dangla are from the lower subbasin (LSB) and the remaining stations are from the upper sub-basin (USB). Accordingly, Bahir Dar meteorological station from the lower and Debre Tabor station from the upper sub-basin have recorded reliable rainfall data for 52 and 40 years, respectively. Moreover, JuneSeptember is the major rainy season (Kiremt), during which period $87-96 \%$ of the annual rainfall has received.
In the USB, during the other months also some amount of rainfall has occurred. The month of July has the highest rainfall in both sub-basins, while in case of the USB; it is August where maximum rainfall comes. After the summer (Kiremt) season ends, the remaining rainfall usually have occurred during the winter season (Bega), and in spring (Belg) season, while in case of the LSB, the rainfall during the Bega and Belg season were very little (Fig. 5).

The monthly mean rainfall amount in the past three decades from the ten stations was aggregated and average values were taken for analysis in the upper and lower sub-basin. Based on these data, the mean, minimum and maximum rainfall amount are higher in the months of June, July, August and September (Table 1). These months are also known as summer season or monsoon rainy season. The agricultural population of the LTSB is totally dependent on this rainfall amount for their crop and livestock production. A slight fluctuation in the rainfall amount, intensity, onset and offset days, directly influences the agricultural activities (NMSA, 2007).

The monthly mean average rainfall of the LTSB also deviated from the mean more in the summer season. But, the coefficient of variations has been relatively small and implying that constant amount of rain comes for most of the times during summer. The correlation coefficient has indicated that the rainfall amount was negatively correlated in the months of April and July for both sub-basins within the periods of the past three decades. It implies that more rainfall decline in those months as compared to the others. Almost for the whole months, the computed slope coefficient is found to be negative, implying that the average rainfall amount declined from time to time across the decades and the slope becomes steeper and steeper by the recent years. It is, therefore, clear that the rain-fed dependent 

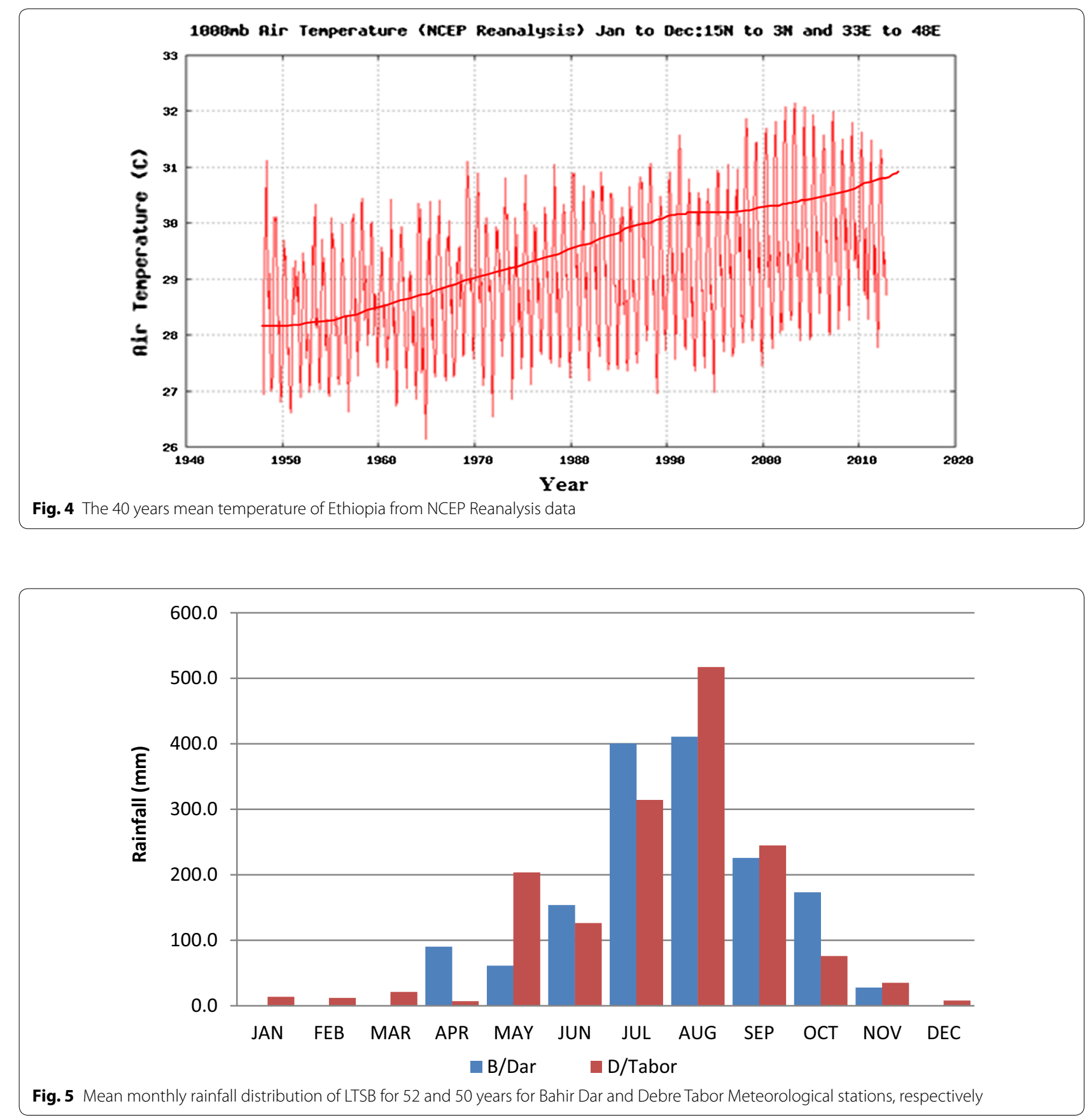

population of LTSB has suffering from surface and ground water shortage for their crop, livestock and for household consumptions. Unless measures should be taken, the adverse impacts of climate change will be more severe on the rural livelihoods since they are the direct victim among the society.

The statistical description of each meteorological station from the upper and the lower sub-basins are stated in Table 2.
The results of those station data analysis revealed that the general declining trend of annual rainfall was recorded for the last three to four decades. Almost all stations recorded minimum annual rainfall during the third decades and the maximum annual rainfall was recorded in the first and second decades. The range of annual rainfall also has indicated that a high variability of annual rainfall was recorded in most of the stations (Table 2). Among the LSB stations, the minimum and maximum 
Table 1 Mean monthly aggregated rainfall data in LTSB descriptive statistics for the last 3 decades (mm)

\begin{tabular}{|c|c|c|c|c|c|c|c|c|c|c|c|c|}
\hline Rainfall level & Jan & Feb & Mar & Apr & May & Jun & Jul & Aug & Sep & Oct & Nov & Dec \\
\hline \multicolumn{13}{|l|}{ Low Sub-basin } \\
\hline Min. & 0.00 & 0.00 & 0.00 & 0.00 & 1.20 & 66.00 & 224.00 & 217.53 & 106.21 & 0.00 & 0.00 & 0.00 \\
\hline Max. & 13.3 & 26.9 & 85.6 & 104.3 & 237.5 & 437.2 & 636.4 & 654.0 & 269.2 & 209.6 & 65.3 & 16.9 \\
\hline Mean & 1.65 & 2.21 & 8.31 & 24.84 & 70.62 & 181.5 & 381.97 & 376.14 & 172.08 & 81.62 & 11.2 & 2.10 \\
\hline SD & 3.22 & 5.87 & 16.60 & 27.27 & 55.88 & 72.95 & 117.06 & 112.30 & 46.48 & 53.56 & 13.9 & 3.99 \\
\hline CV & 2.29 & 3.31 & 2.49 & 1.18 & 0.90 & 0.47 & 0.31 & 0.32 & 0.31 & 0.71 & 1.50 & 2.18 \\
\hline r & 0.15 & 0.20 & 0.12 & -0.09 & 0.01 & 0.01 & -0.27 & 0.41 & 0.24 & 0.12 & 0.45 & 0.04 \\
\hline Slope & 0.00 & -0.04 & -0.07 & -0.27 & 0.40 & 1.34 & -9.55 & -5.36 & -2.66 & -0.65 & -0.0 & -0.03 \\
\hline \multicolumn{13}{|c|}{ Upper Sub-basin } \\
\hline Min. & 0.00 & 0.00 & 0.00 & 5.50 & 10.30 & 73.00 & 234.00 & 190.20 & 80.10 & 2.90 & 0.50 & 0.00 \\
\hline Max. & 81.4 & 81.1 & 98.00 & 118.30 & 211.50 & 345.00 & 592.10 & 628.50 & 321.00 & 305.0 & 76.20 & 82.50 \\
\hline Mean & 5.46 & 7.99 & 34.65 & 49.94 & 92.49 & 151.70 & 396.59 & 375.94 & 188.53 & 74.90 & 22.78 & 11.86 \\
\hline SD & 14.0 & 18.30 & 33.42 & 33.51 & 67.25 & 59.43 & 83.57 & 92.09 & 55.53 & 65.51 & 17.30 & 15.96 \\
\hline$C V$ & 2.56 & 2.29 & 0.96 & 0.67 & 0.73 & 0.39 & 0.21 & 0.24 & 0.29 & 0.87 & 0.76 & 1.35 \\
\hline r & 0.26 & -0.04 & -0.23 & 0.22 & 0.32 & 0.19 & 0.17 & 0.40 & 0.33 & 0.21 & 0.05 & -0.12 \\
\hline Slope & 0.31 & -0.37 & -0.77 & -0.51 & -0.88 & 0.41 & -4.46 & -5.07 & -0.84 & -1.51 & -0.19 & -0.06 \\
\hline
\end{tabular}

Table 2 Mean annual rainfall of each station in LTSB

\begin{tabular}{|c|c|c|c|c|c|c|c|c|c|c|}
\hline Station & No. years & $\operatorname{Min}(\mathrm{mm})$ & Obs. year & $\operatorname{Max}(\mathrm{mm})$ & Obs. year & Mean & Sd & Cv & $\mathbf{R}$ & $\mathrm{S}$ \\
\hline B/Dar & 53 & 894.6 & 1982 & 2036.9 & 1973 & 1429.6 & 223.9 & 0.16 & -0.24 & -3.57 \\
\hline Yifag & 33 & 719.3 & 1991 & 1345.0 & 1982 & 1023.9 & 174.4 & 0.17 & -0.41 & -7.41 \\
\hline Hamusit & 44 & 1000 & 2005 & 2216.6 & 1985 & 1475.1 & 316.1 & 0.22 & -0.28 & -6.81 \\
\hline Zeghie & 34 & 823.6 & 1991 & 1896.7 & 1999 & 1499.7 & 247.8 & 0.17 & -0.26 & -10.1 \\
\hline Dangila & 35 & 1180.2 & 1968 & 1960.2 & 1999 & 1556.3 & 223.6 & 0.14 & -0.12 & -6.9 \\
\hline Maksegnit & 32 & 721.0 & 2011 & 2123.5 & 1983 & 1215.6 & 371.6 & 0.31 & -0.43 & -16.9 \\
\hline D/Tabor & 39 & 767.5 & 2012 & 2319.4 & 1980 & 1400.3 & 422.2 & 0.30 & -0.32 & -11.6 \\
\hline Injibara & 30 & 1612 & 2005 & 2828.9 & 1999 & 2181.1 & 281.1 & 0.13 & -0.42 & -13.1 \\
\hline Sekela & 32 & 1187 & 1981 & 2383.7 & 2006 & 1795.7 & 344.8 & 0.20 & -0.27 & -22.3 \\
\hline Gundil & 31 & 1798 & 1995 & 2721.1 & 2005 & 2348.3 & 268.4 & 0.11 & -0.45 & -26.4 \\
\hline
\end{tabular}

$S d$ standard deviation, $c v$ coefficient of variations, $r$ Correlation Coefficient, $S$ slope

annual mean rainfall were recorded by Yifag $(1023.9 \mathrm{~mm})$ and Dangla (1556.3 $\mathrm{mm})$, respectively. Likewise, from the USB, the minimum and maximum mean annual rainfall was recorded by Maksegnit $(1215.6 \mathrm{~mm})$ and Injibara $(2828.9 \mathrm{~mm})$, respectively. The average yearly rainfall of the LTSB had a range from $719.3 \mathrm{~mm}$ at the Yifag station to $2828.9 \mathrm{~mm}$ at Injibara station. These values indicate that there has been high annual rainfall variability across the sub-basins.

During the past three to four decades, the rainfall has deviated annually with maximum $422.2 \mathrm{~mm}$ from the mean in the case of Debire Tabor station and a minimal deviation of $174.43 \mathrm{~mm}$ in the case of Yifag station. The trend on the decadal basis was also analyzed to determine the changes over time within the study period. In order to detect statistically significant changes in the annual rainfall at the sub-basin level and inter stations, a timeseries study was undertaken. The parameter estimate of the slope was then tested for statistical significance using the paired sample t test.

In order to clarify the descriptive information, linear regression was fitted and the slope was determined and paired samples t test was run to check their correlation. The slope has shown a declining trend of rainfall within the stated period. The slope of a line was also used as a measurement of how many units it goes up or down for every year to see the change of annual rainfall conditions. As it is depicted from Table 2, the annual mean rainfall has decreased almost for all stations and it is found to be statistically significant at the $5 \%$ level of significance. This has shown that the climate is changing from time to time within the stated decades. The maximum decline 


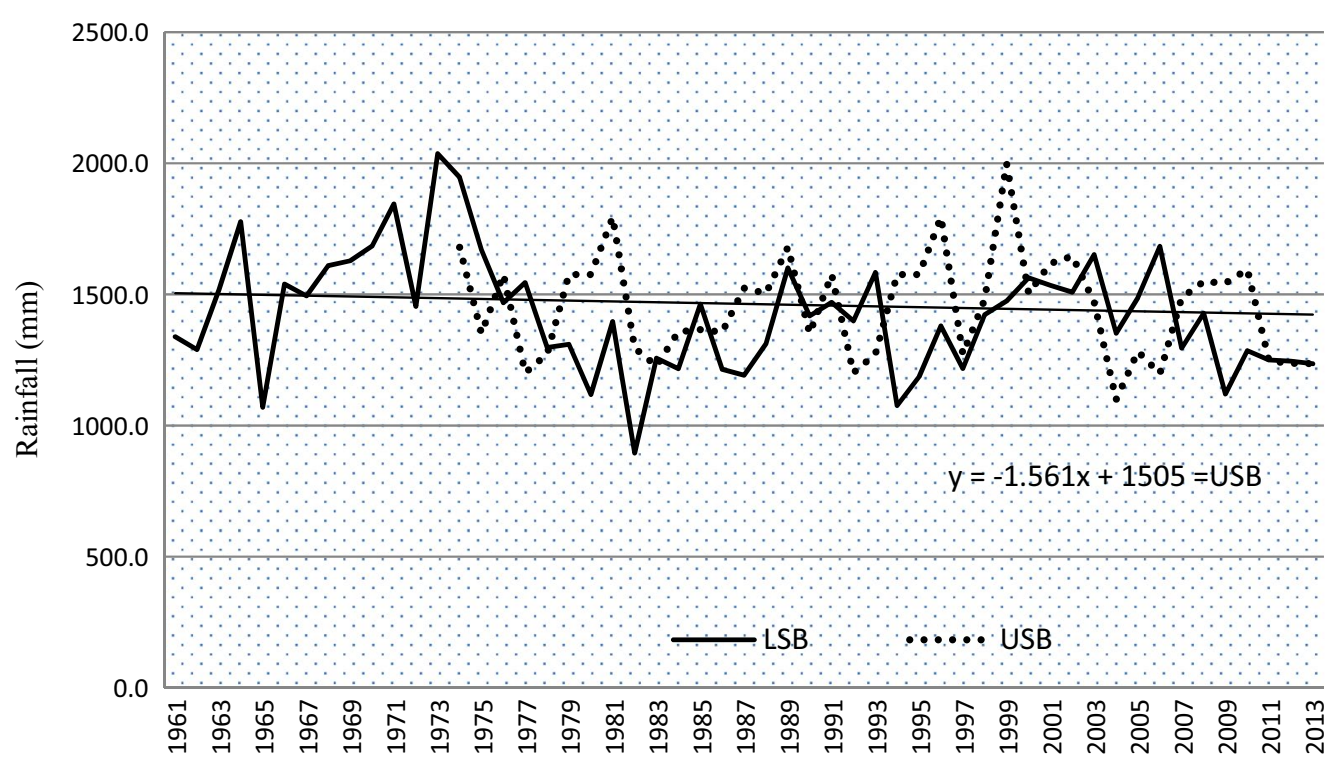

Fig. 6 Annual average rainfall amount trends of LTSB

was recorded by Gundil with a slope of -26.4 from the USB and the minimum from Bahir Dar (-3.57) LSB. The negative sign indicates that decline from the slope of each mean annual rainfall record.

The coefficient of variance analysis has indicated that a significant annual rainfall variation was recorded from the whole weather stations with maximum at Maksegnit (31\%) and minimum from the Gundil (11 \%) station. According to Hare (2003), category of severity, among the LTSB stations annual rainfall variability recorded by Maksegnit (31 \%) and Debre Tabor (30\%) were very severe, Hamusit (22) and Sekela (20\%) were moderately sever and the remaining stations were severe. Significant annual rainfall variability implies that climate change resulted in climate variability and extreme weather conditions. These were also confirmed by the correlation coefficient of the annual rainfall change and variability. All of the weather stations in the sub-basin have shown a negative correlation with the time period in the last three to four decades.

In general, mean annual rainfall straight lines for all stations in LTSB have slopes which were applied to examine the least-square regression lines, compared with the corresponding values of the correlation coefficient and resulted as negative value. From this analysis, it would be noticed that every year that the data has a negative correlation coefficient, the slope of the regression line is negative. It should be apparent from this observation that there is a link between the sign of the correlation coefficient and the side of the least squares line and one variable confirms the other and clearly annual rainfall amount in LTSB shows significant variability and declining trends. As it is indicated in Fig. 6, there has been a general decreasing trend in the average amount of annual rainfall. The trend line shows that the average amount of annual rainfall has decreased by a factor of 3.947 in the lower sub-basin and by 1.561 in the upper one for each year. As indicated in the trend line equations the slope has a negative value, which implies a decreasing of the average amount of annual rainfall.

This implies that agricultural activities are highly vulnerable to such changes. Since agriculture is the backbone of the county's economy, productivity fluctuation directly influences the growth domestic products (GDP). This should be aggravated because of the low adaptive capacity of the rural poor and their full dependency on rain-fed agriculture for their livelihoods. Therefore, it is clear from the analysis that climate change is vividly happening in Ethiopia as well as the LTSB and appropriate adaptation strategies should be properly designed and implemented.

\section{Annual rainfall Mann-Kendall's trend-test analysis of each station}

On running the Mann-Kendall's test (MT) on annual rainfall data, the results in Table 3 are obtained from the ten stations data of the LTSB. The MT is based on the calculation of Kendall's tau (measures of connection between two successive annual rainfall years). The analysis results shows that most of the stations successive annual rainfall years are negatively related. It is found to be statistically significant annual rainfall irregularities 
Table 3 Annual rainfall Mann-Kendall's trend test results

\begin{tabular}{|c|c|c|c|c|c|c|}
\hline \multirow[t]{2}{*}{ Station } & \multirow[t]{2}{*}{ No. years } & \multicolumn{5}{|c|}{ Mann-Kendall's test, (H0: there is no trend) } \\
\hline & & Mann-Kendall stat (S) & Var. (S) & Kendall's tau & $P$-value & $a$ \\
\hline Bahir Dar & 49 & -231.00 & 16991.667 & -0.168 & $0.078^{*}$ & 0.05 \\
\hline Yifag & 33 & -158.000 & 4165.333 & -0.299 & $0.015^{* *}$ & 0.05 \\
\hline Hamusit & 44 & -196.000 & 9766.000 & -0.208 & $0.048^{* *}$ & 0.05 \\
\hline Zeghie & 34 & -230.00 & 16900.667 & -0.192 & $0.040^{* *}$ & 0.05 \\
\hline Dangila & 35 & 5.000 & 1257.667 & 0.022 & $0.910^{*}$ & 0.05 \\
\hline Maksegnit & 32 & -170.000 & 3798.000 & -0.344 & $0.006^{* *}$ & 0.05 \\
\hline DebreTabor & 39 & -178.000 & 7360.000 & -0.229 & $0.039^{* *}$ & 0.05 \\
\hline Injibara & 30 & -28.000 & 1256.667 & -0.121 & $0.446^{*}$ & 0.05 \\
\hline Sekela & 32 & 47.000 & 1257.667 & 0.203 & $0.195^{*}$ & 0.05 \\
\hline Gundil & 31 & 46.000 & 1200.667 & 0.201 & $0.105^{*}$ & 0.05 \\
\hline
\end{tabular}

* As the computed $p$-value is greater than the significance level alpha $=0.05$, one cannot reject the null

hypothesis $\mathrm{HO}$

** As the computed p-value is lower than the significance level alpha $=0.05$ reject the null hypothesis $\mathrm{H} 0$

across the whole recorded years in LTSB at the $5 \%$ level of significance. If the $p$ value is less than the significance level $\alpha=0.05$, Ho, (there is no trend), hence, the hypothesis is not accepted. Rejecting Ho indicates that there is a trend in the time series, while accepting Ho indicates no trend is detected. Rejecting the null hypothesis implies that the result is said to be statistically significant at $\alpha=0.05$ level of significance (Yifag, Hamusit, Zeghie, Maksegnit, and D/Tabor stations). For this test result, the null hypothesis is accepted for Bahir Dar, Dangila, Injibara, Sekela and Gundil station data. In these stations, annual rainfall has shown no trend as the computed p-value is greater than the significance level $\alpha=0.05$ (Table 3).

The Mann-Kendall's test (MT) gives an interesting insight about the annual rainfall data for the LTSB. The MK test statistic (S) has indicated that there has been a decreasing rainfall trend of most of the stations' data. On further analyzing the ' $\mathrm{S}$ ' statistics, it becomes evident that there was conformity in magnitude of the statistics when the altitudinal factor is taken into consideration. That is for the stations of Dangila, Injibara, Sekela and Gundil, the 'S' statistics is near to 1200 . While the remaining stations, the ' $\mathrm{S}$ ' statistics is variable and difficult to categorize based on altitude. It might increase by one year and decrease by the other with a different rate and clearly indicates that climate change is reflected by making erratic rainfall in LTSB. On the other hand, Yifag, Hamusit, Zeghie, Maksegnit and Debre Tabor stations annual rainfall record has shown better trends as the computed $\mathrm{p}$-value is lower than the significance level $(\alpha=0.05)$. Based on the above results, it is of immense importance to discuss the ecological, economic and social impacts that could result if decreasing rainfall trends continue in the future. For rural farmers who have been vulnerable to drought, water stress and erratic nature of rainfall, appropriate adaptation strategies should have to be designed and implemented. The vulnerability of rural households might further be aggravated if extreme rainfall episodes continue in the future and consequently result in drought and surface and ground water losses due to evaporation and over utilization.

\section{Temperature trends and MT of the LTSB}

The time series mean monthly temperature was analyzed across the upper and lower sub-basins in the same procedure to that of the rainfall data. The stations which are found in the USB and LSB mean monthly temperature value were aggregated and representative single mean value was taken for each sub-basin analysis. Accordingly, the whole months mean temperature for the last 52 years in the LSB has stated in Table 4. The slope of the whole months shows that a positive value implying an increase in the mean monthly temperature. The mean, minimum and maximum temperature has recorded in the months of January and May respectively in the LSB. Moreover, December and January were the months of high variations of mean monthly temperature recorded. Moreover, December was the month of high deviation of temperature occurrence. There is also a positive correlation between the monthly mean temperature record and the time period. This might be the case that temperature is increasing from time to time in the LSB as a result of global climate change.

Likewise, the USB stations were combined and analyzed for the long year's monthly mean trend analysis for the last 40 years. In the case of the USB, the minimum and maximum temperatures were in the months of February 
Table 4 Lower and USB monthly mean temperature descriptive statistics

\begin{tabular}{|c|c|c|c|c|c|c|c|c|c|c|c|c|}
\hline Temperature & Jan & Feb & Mar & Apr & May & Jun & Jul & Aug & Sep & Oct & Nov & Dec \\
\hline \multicolumn{13}{|l|}{ LSB (52 years) } \\
\hline Min. & 14.4 & 14.8 & 17.3 & 18.5 & 18.9 & 18.2 & 14.5 & 15.4 & 15.6 & 16.4 & 15.1 & 14.5 \\
\hline Max. & 18.9 & 21.3 & 23.2 & 24.1 & 24.6 & 22.1 & 20.3 & 20.2 & 20.8 & 20.9 & 20.6 & 19.6 \\
\hline Mean & 17.1 & 18.6 & 20.7 & 21.6 & 21.6 & 20.4 & 18.8 & 18.7 & 19.0 & 19.4 & 18.4 & 17.0 \\
\hline SD & 1.2 & 1.4 & 1.2 & 1.6 & 1.1 & 1.0 & 1.1 & 0.9 & 0.9 & 0.9 & 1.1 & 1.3 \\
\hline $\mathrm{CV}$ & 7.3 & 7.5 & 6.0 & 7.2 & 4.9 & 4.9 & 5.7 & 4.7 & 4.7 & 4.8 & 6.0 & 7.7 \\
\hline$r$ & 0.46 & 0.70 & 0.61 & 0.61 & 0.67 & 0.73 & 0.55 & 0.69 & 0.95 & 0.84 & 0.81 & 0.82 \\
\hline Slope & 0.04 & 0.06 & 0.04 & 0.07 & 0.04 & 0.34 & 0.02 & 0.03 & 0.03 & 0.04 & 0.04 & 0.05 \\
\hline \multicolumn{13}{|l|}{ USB (40 years) } \\
\hline Min. & 14.30 & 12.82 & 14.60 & 16.08 & 15.50 & 14.55 & 13.44 & 13.35 & 13.54 & 13.49 & 13.38 & 13.50 \\
\hline Max. & 16.75 & 18.03 & 22.00 & 19.71 & 19.12 & 17.65 & 15.60 & 17.14 & 16.05 & 16.05 & 16.00 & 15.56 \\
\hline Mean & 15.30 & 16.31 & 17.19 & 17.41 & 17.22 & 16.10 & 14.40 & 14.42 & 14.73 & 14.78 & 14.75 & 14.71 \\
\hline SD & 0.62 & 1.13 & 1.35 & 0.97 & 0.90 & 0.69 & 0.43 & 0.69 & 0.59 & 0.61 & 0.57 & 0.53 \\
\hline$C V$ & 4.1 & 7.0 & 7.9 & 5.6 & 5.2 & 4.3 & 3.0 & 4.8 & 4.0 & 4.1 & 3.9 & 3.6 \\
\hline$r$ & 0.55 & 0.77 & 0.55 & 0.79 & 0.75 & 0.57 & 0.09 & 0.464 & 0.59 & 0.45 & 0.61 & 0.41 \\
\hline Slope & 0.01 & 0.04 & 0.03 & 0.04 & 0.04 & 0.02 & 0.00 & 0.03 & 0.03 & 0.02 & 0.02 & 0.01 \\
\hline
\end{tabular}

and March, respectively. It is found to be the month of February when high deviation of mean temperature was recorded. Similarly, the months of December and January time series analysis has shown that the highest variations of mean monthly temperature were recorded. The correlation coefficient indicates that months of April and May showed relatively higher positive correlation. Similar to the lower sub-basin, the upper sub-basin also has a positive slope value indicating that there was a successive mean monthly temperature change for the past 40 years (Table 4).

\section{Mann-Kendall trend test (MT test) of annual temperature}

For the temperature data recorded from the lower and upper sub-basins, the average value was analyzed using the MT test and the results revealed that there has been an increasing trend of the mean temperature in the LSB as the computed $\mathrm{p}$-value is lower than the significance level alpha $=0.05$, one should reject the null hypothesis $\mathrm{H}_{0}$. It implies that the MT-test is statistically significant for the mean temperature which has shown an increasing trend. However, the minimum and maximum temperature increasing trend analysis is found to be statistically not significant as the computed p-value is greater than the significance level alpha $=0.05$, one cannot reject the null hypothesis $\left(\mathrm{H}_{0}\right)$. In other words, the minimum and maximum temperature increasing trends are not significant in the lower sub-basin (Table 5).

In the case of the USB, the minimum temperature showed a significant increasing trend as the computed $\mathrm{p}$-value is lower than the significance level alpha $=0.05$. It becomes essential to understand how this may also affect the prevalence of malaria, plant and animal pests as a result of change in the minimum temperature in the USB of Lake Tana. This result is in line with the research outputs of the national meteorological agency. The average annual mean minimum temperature throughout the country indicated an increase of $0.37{ }^{\circ} \mathrm{C}$ every decade (NMA 2007).

On the other hand, the maximum and the mean temperature showed no significant increasing trends as the computed $\mathrm{p}$-value is greater than the significance level $\alpha=0.05$, one cannot reject the null hypothesis $\mathrm{H}_{0}$. A fitting of linear trend lines showed that there is an increasing temperature trend for all stations, although the slopes are small in magnitude (Fig. 7).

\section{Conclusions}

Ethiopia is vulnerable to climate variability, and climate change is likely to increase the frequency and magnitude of disasters. Adverse impacts of climate change may worsen existing social and economic challenges of the whole country, particularly where people are dependent on resources that are sensitive to climate change and summer rain-fed agriculture. Past and current investments and disaster interventions in the country are more focused on recovery from a disaster than on the creation of adaptive capacity. Increased capacity to manage future climate change and weather extremes can reduce the magnitude of economic, social and human damage. Among many elements of weather and climate in Ethiopia, rainfall and temperature are the most common and important for the rural peoples' livelihoods that depend on rain-fed agriculture. Analysis of the 40 years annual 
Table 5 Mann-Kendall trend test of annual temperature

\begin{tabular}{|c|c|c|c|c|c|c|}
\hline \multicolumn{7}{|c|}{$\mathrm{H}_{0}$ : There is no trend } \\
\hline Temperature & No. years & Kendall's (S) & Var. (S) & Kendall's tau & $P$-value & $a$ \\
\hline \multicolumn{7}{|l|}{ LSB } \\
\hline Tmax. & 49 & 96.000 & 4165.33 & 0.182 & $0.141^{*}$ & 0.05 \\
\hline Tmin. & 33 & -55.000 & 4548.33 & -0.098 & $0.423^{*}$ & 0.05 \\
\hline Tmean & 44 & 392.000 & 16991.33 & 0.285 & $0.003^{* *}$ & 0.05 \\
\hline \multicolumn{7}{|l|}{ USB } \\
\hline Tmax. & 34 & 35.000 & 7351.00 & 0.045 & $0.692^{*}$ & 0.05 \\
\hline Tmin. & 35 & 264.000 & 7346.00 & 0.342 & $0.002^{* *}$ & 0.05 \\
\hline Tmean & 32 & 143.000 & 7363.67 & 0.184 & $0.098^{*}$ & 0.05 \\
\hline
\end{tabular}

${ }^{*}$ As the computed $\mathrm{p}$-value is greater than the significance level alpha $=0.05$, one cannot reject the null $\mathrm{H}_{0}$

** As the computed $\mathrm{p}$-value is lower than the significance level $\mathrm{a}=0.05$, one can reject the null hypothesis $\mathrm{H}_{0}$

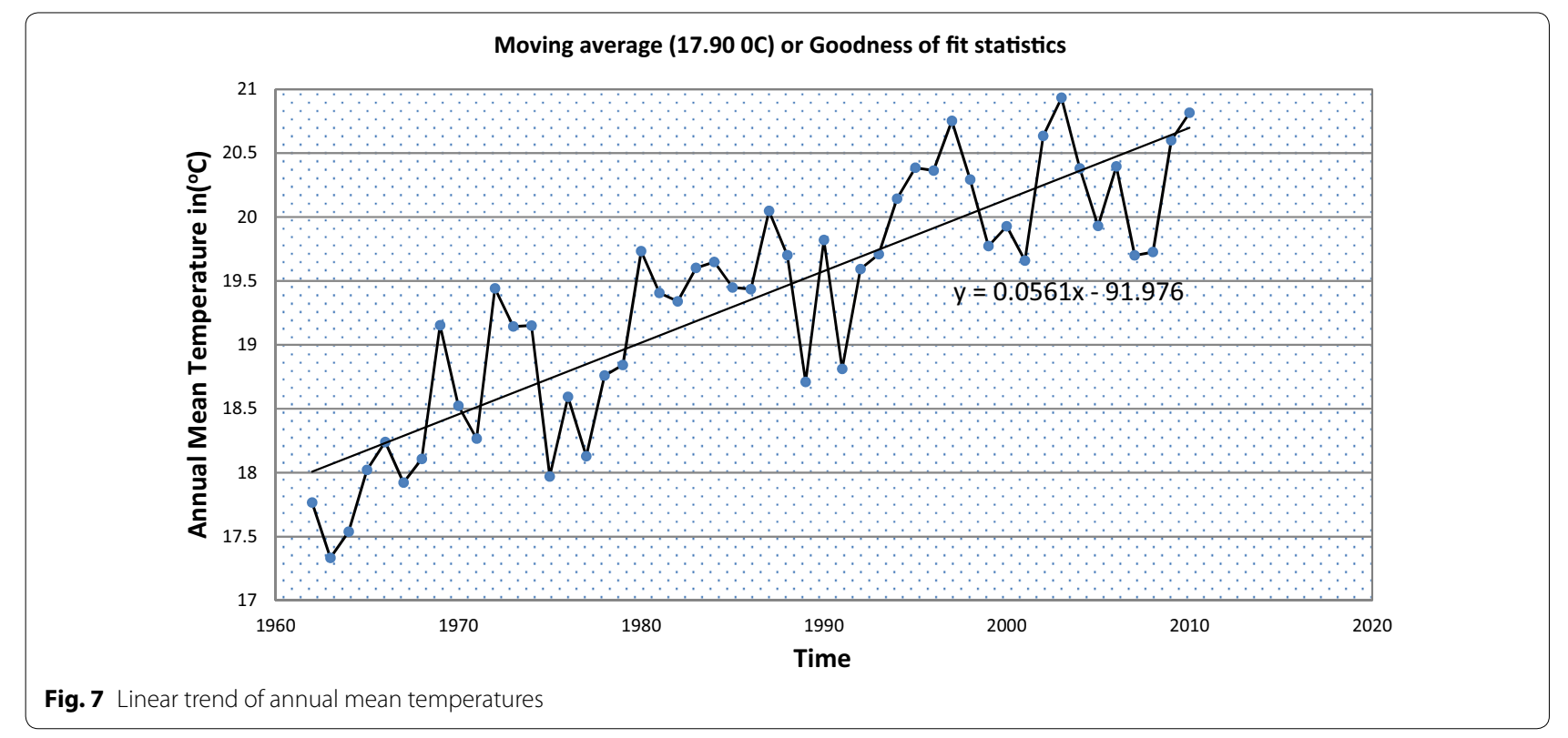

total rainfall data from 109 representative ground based meteorological stations of the country, indicated a coefficient of variation ranging from 20 to $89 \%$. Of the 109 stations considered, 17 had above $42 \%$ coefficient of variation highlighting the extreme variability of rainfall. However, recorded meteorological data analysis of temperature indicates that increasing trends observed almost in all parts of the country. According to the Mann-Kendall monotonic trend analysis test, the maximum and minimum temperature analysis resulted in a general increasing trend. Whereas, rainfall amount resulted in a general decreasing trend based on the average recorded values of the different stations from the LTSB. To recommend the concerned body, development planners should design strategies and plans by taking into account a declining summer rainfall and increasing temperature impacts on rural livelihoods.

\section{Authors' contributions}

SA has made substantial contributions in conception design, acquisition of data, interpretation of results and leading the overall activities of the research; He has given also the final approval of the version to be published. BG and GF have been involved in data collection, entry, coding, and analysis. YGS contributed in writing, drafting the manuscript, revising it critically for important intellectual content. All authors read and approved the final manuscript.

\section{Acknowledgements}

This study would never be completed without the contribution of many people to whom we would like to express our gratitude. The administrative kebele's development agents, district agricultural officials, local guiders, committee leaders and respondent households in each of the sampling kebeles were indispensable for the successful completion of the field work. We would like also to acknowledge people who contributed their knowledge and time in data collection and entry processes. 


\section{Competing interests}

The authors declare that they have no competing interests

Received: 15 October 2015 Accepted: 23 November 2015 Published online: 09 December 2015

\section{References}

Compo GP, Whitaker PD, Sardeshmukh N, Matsui RJ, Allan X, Yin BE, Gleason RS, Vose G, Rutledge P, Bessemoulin S, Brönnimann M, Brunet Rl, Crouthamel AN, Grant PY, Groisman PD, Jones M, Kruk AC, Kruger GJ, Marshall M, Maugeri HY (2011) The Twentieth Century Reanalysis Project. Quarterly J Roy Meteorol Soc 137:1-28. doi:10.1002/qj.776

CSA (Central Statistical Agency) (2007) Central Statistical Agency Population and Housing Census of Ethiopia, Addis Ababa. Retrieved August, 2013, from CSA database

Gebre H, Kindie T, Girma M, Belay K (2013) Trend and variability of rainfall in Tigray, Northern Ethiopia: analysis of meteorological data and farmers' perception. Acad J Agric Res 1(6):88-100

Hare W (2003) Assessment of Knowledge on Impacts of Climate Change, Contribution to the Specification of Art, 2 of the UNFCCC, WBGU

IPCC (2001a) Climate change 2001, the scientific basis. Cambridge University Press, Cambridge

IPCC (2001b) Climate change 2001: impacts, adaptation and vulnerability. Cambridge University Press, Cambridge

IPCC (2003) Good practice Guidance for Land use, Land use change and Forester. Institute for Global Environmental Strategies (IGES) for the IPCC Japan, 240-0115
IPCC (2007) Synthesis Report. Contribution of Working Group I, II and III to the Fourth Assessment Report of the Intergovernmental Panel on climate change Core writing team. In: Pachauri RK, Reisinger A (eds). IPCC, Geneva, Switzerrland, p 104

IPCC (2007) Synthesis Report. Contribution of Working Group I, II and III to the Fourth Assessment Report of the Intergovernmental Panel on climate change Core writing team. In: Pachauri RK, Reisinger A (eds) IPCC, Geneva, Switzerland, p 104

IPCC (2014) Climate change synthesis report summary for policy makers. Retrieved 2014 from http://www.ipcc.ch/pdf/assessment-report/ar5/syr/ SYR_AR5_SPMCorr1.pdf

Keredin TS, Annisa M, Surendra B, Solomon A (2013). Long years comparative climate change trend analysis in terms of temperature, coastal Andhra Pradesh, India. Refer J Res Sci Technol 2(7). ISSN 2277-1174

NMSA (National Meteorological Service Agency) (2007) Climate Change National Adaptation Program of Action (NAPA) of Ethiopia. NMSA, Addis Ababa. Retrieved June 23, 2013, from NMSA database

Philip A, Augistine Y, Abindaw B (2014) Impact of climate variability on smallholder households and indigenous coping strategies in Bonga district. Int J Develop Res 4(3):693-699

UNFCCC (United Nations Framework conventions on Climate Change) (2006) Background paper on Impacts, Vulnerability and adaptation to climate change in Africa. 1 CP.10, Accra, Ghana, September 2006

Watson RT, IPCC Core Writing Team (eds) (2001) Climate Change 2001, Synthesis Report. A Contribution of Working Groups I, II, and III to the Third Assessment Report of the Intergovernmental Panel on Climate Change. Cambridge University Press, Cambridge

\section{Submit your manuscript to a SpringerOpen ${ }^{\circ}$ journal and benefit from:}

- Convenient online submission

- Rigorous peer review

- Immediate publication on acceptance

- Open access: articles freely available online

- High visibility within the field

- Retaining the copyright to your article

Submit your next manuscript at $\boldsymbol{~ s p r i n g e r o p e n . c o m ~}$ 